\title{
LAS ESCRITORAS SALVADOREÑAS A PRINCIPIOS DEL SIGLO XX: EXPECTATIVAS Y PERCEPCIONES SOCIO-CULTURALES
}

\author{
Dra. Sonia Priscila Ticas \\ Profesora de Lengua y Literatura Latinoamericana \\ Linfield College, Oregon USA
}

\begin{abstract}
RESUMEN
Este artículo traza aspectos de la historia cultural, social y educativa de las mujeres salvadoreñas a principios del siglo veinte. Se enfoca en la literatura de mujeres y los discursos contenidos en ella con el fin de dilucidar cuáles eran las preocupaciones de las intelectuales y cómo usaron la escritura para ubicar el tema de la mujer en la esfera pública. Asímismo se da un contexto sobre la educación y el ambiente socio cultural en que se formaron muchas de estas escritoras tomando en cuenta las percepciones que en la época se tenían sobre el feminismo.
\end{abstract}

Descriptores: Mujeres. Escritoras. Percepciones socio-culturales. El Salvador. Principios siglo $\mathrm{XX}$.

\section{INTRODUCCIÓN}

El entorno social y cultural de las mujeres salvadoreñas a principios del siglo veinte se regía en su mayoría por la indiferencia sobre la necesidad de hacer de este sector de la población un actor social activo. A las mujeres, como era de esperarse, se les seguía consignando al espacio privado del hogar donde pudieran desenvolverse en su papel de madre y esposa. Esta ideología se revela tanto en la educación así como en los medios de comunicación y en la literatura escrita por miembros de ambos sexos. Las escritoras e intelectuales que proponían una agenda femenina más consecuente con la realidad 
cambiante de la época enfrentaron una serie de obstáculos para llegar a tener cierta visibilidad en la esfera cultural y social. No se podía hablar de feminismo pues el término equivalía a bancarrota familiar e inmoralidad. Fue necesario entonces buscar discursos alternativos para denunciar la opresión y discriminación de la mujer. El presente trabajo propone examinar la situación socio cultural de la mujer salvadoreña a principios del siglo veinte poniendo especial énfasis en las décadas del veinte y treinta, época en que se sentaron las bases para un movimiento feminista que había de florecer a mediados del siglo. Nos enfocamos en la figura de la mujer escritora pues debido a su cultura letrada es quien tuvo un mayor acceso a la arena pública.

\section{EL OFICIO DE ESCRITORA: RETOS Y OBSTÁCULOS}

Al dar inicio el siglo veinte había pocas mujeres que se dedicaban al quehacer literario. Su acceso a la esfera cultural era doblemente difícil pues debido a su sexo se les inculcaba la vida doméstica y familiar en vez de los estudios académicos. En la sociedad de fin de siglo diecinueve siempre estuvo el quehacer cultural en manos de grupos élites como "La juventud salvadoreña" que se crearon precisamente para estimular las letras entre los jóvenes universitarios (Gallegos 1996: 62), lo cual excluye casi por completo a las mujeres,

pues eran contadas las que en la época asistían a la universidad. ${ }^{1}$ A pesar de los obstáculos presentes, sin embargo, hubo mujeres que sí publicaron sus creaciones, aunque de manera esporádica, en periódicos o revistas. Luis Gallegos Valdés y David Escobar Galindo en su Antología de poesía femenina salvadoreña (1975) identifican, por ejemplo, a cinco poetas 
decimonónicas cuyos poemas son conocidos gracias a compilaciones como la Guirnalda salvadoreña y el Parnaso salvadoreño.

Publicar ha sido problema común tanto a hombres como a mujeres en el país, pues no siempre se ha contado con los recursos para fomentar el cultivo de las letras nacionales. Cuando los escritores lograban darse a conocer, solía ser a través de periódicos pero raramente por medio de un libro, a menos que se tratara de alguien con mayores recursos económicos. Este es precisamente el caso de Claudia Lars (1899-1974), la más destacada de las escritoras del siglo veinte, para quien transcurre toda una década de publicaciones en revistas y periódicos locales tanto como regionales antes que su primera obra poética, Estrellas en el pozo, viera la luz pública en 1934.

Más allá de su talento, Lars necesitó del padrinazgo y el apoyo de figuras importantes de las letras centroamericanas como Joaquín García Monge, director del Repertorio Americano, revista de gran circulación en todo el continente, y el poeta nicaragüense Salomón de la Selva quien le sirvió de maestro cuando recién comenzaba a dar sus primeros pasos en la poesía. Demás está decir que no todas las mujeres escritoras de la época tuvieron este tipo de guía intelectual, ni contaron tampoco con los medios económicos ni la cultura literaria que les permitieran dedicarse por completo al oficio poético como sí lo hizo Lars en sus inicios. Y aún cuando las escritoras tuvieran estos factores a su favor, la expectativa general era que su producción se enmarcara dentro de los parámetros temáticos pre-establecidos para la escritura de mujeres; es decir, el mundo de la casa con sus experiencias maternas y el amor romántico (Carrera 1956: 230). De no ser así, era poco probable que fueran aceptadas en un medio donde la mujer servía más de musa que de creadora. 
La limitada presencia de figuras femeninas en el ambiente cultural nacional es evidencia de que no se ha considerado a la mujer como sujeto capaz de contribuir al desarrollo cultural del país. El resultado más grave de esta situación es que hay huecos profundos en el conocimiento de lo que produjeron las primeras poetas y las condiciones en que lo hicieron. Las antologías de la literatura de fin de siglo de tipo Guirnalda y Parnaso parecen indicar que la producción femenina fue escasa, pues no se mencionan más de dos o tres poemas dignos de ser publicados, según los criterios de los compiladores. Este trato que ha sufrido la mujer escritora es común en toda la historiografía literaria centroamericana aún en el siglo veinte como apunta Janet Gold (2000):

“...No es sorprendente observar cómo aparecen las mujeres en esas clásicas historias. En algunas simplemente son invisibles y, además, su ausencia ni se menciona. Otras reconocen la existencia de mujeres que escriben y de musas; sin embargo, son incapaces de integrar esta presencia en una visión abarcadora de lo que es o lo que hace la literatura en el contexto centroamericano. Como consecuencia de esta miopía histórica y de género, las mujeres se vuelven apéndices, un capítulo al final de un libro, o un párrafo al final de un capítulo, como si el historiador de repente recordara al otro sexo y en un gesto magnánimo las juntara al final, tratándolas como creadoras menores de literatura, que hacen lo mismo que los hombres, aunque con menos maestría, o hacen cosas femeninas..." (Gold 2000: 14).

En el caso salvadoreño estas observaciones se aplican con bastante precisión. En la historia canónica de la literatura escrita por Luis Gallegos Valdés, Panorama de la literatura salvadoreña, la única figura femenina que recibe atención por separado es Claudia Lars. Todas las otras poetas aparecen agrupadas bajo la rúbrica de "Letras femeninas" (Gallegos 1996: 275-287). En ésta, al igual que en las anteriores colecciones antológicas como la de La juventud, se presenta a las poetas con brevísimas notas biográficas que no permiten discernir cuál era el entorno socio cultural en que vivían. Nos encontramos con el mismo problema en la antología de Poesía Femenina de El Salvador 
(Escobar y Gallegos: 1976), donde se hace una selección basada en métodos cronológicos. Sigue faltando entonces una investigación más exhaustiva que dé cuenta de la producción literaria femenina y sus repercusiones en la vida social, cultural y política del país. Sólo así se podrá entender mejor y apreciar la vida y la literatura de mujeres a lo largo del siglo pasado.

En el campo de la educación femenina la situación es básicamente la misma. Es un área de conocimiento que hasta muy recientemente había sido ignorada casi por completo. Por fortuna, la investigación de Carlos Cañas Dinarte contenida en su ensayo, Las hijas de Minerva, Hacia una historia educativa y cultural de las mujeres salvadoreñas, ha rescatado del olvido histórico a las mujeres más destacadas del siglo diecinueve y ha rastreado el desarrollo de lo que en el país representan los primeros esfuerzos por crear centros de educación femenina. La situación social que se deslinda de los datos recopilados en esta obra nos sirve de trasfondo para estudiar el medio en que nacieron y se formaron las escritoras e intelectuales de principio de siglo veinte.

\section{UNA INCIPIENTE EDUCACIÓN FEMENINA}

Tras las gestas independentistas se introduce en el país un sistema de enseñanza gratuita para varones, aunque con muchas limitaciones en cuanto a recursos. Para las jovencitas no es hasta 1847 cuando bajo auspicio oficial se funda un centro de educación secundaria impulsado por un funcionario que quería que su futura esposa tuviera una instrucción mínima que le permitiera administrar el hogar de manera eficiente (CañasDinarte 1999: 22-23). Las clases que se impartían consistían de artes manuales como la 
costura y otras materias como la aritmética básica (Cañas-Dinarte 1999: 22-23). Es decir, que esta incipiente educación tenía un fin más bien decorativo y en menor escala práctico pues se configuraba puramente en la formación de una buena ama de casa que hiciera funcionar a perfección todos los aspectos de la vida hogareña.

Este primer proyecto terminó en clausura en parte debido a la resistencia del patriarcado que no veía con buenos ojos ningún tipo de instrucción para la mujer (CañasDinarte 1999: 27). La nota positiva fue que entre las alumnas más destacadas surgieron las primeras maestras que luego proseguirían a abrir escuelas en varios departamentos de la república. Esto significó un esfuerzo titánico en un país donde el analfabetismo llegaba a más de un noventa y cinco por ciento (citado en Cañas-Dinarte 1999: 22). Hacia final del siglo, la política educativa progresista del gobierno de Menéndez facilitó la apertura de una serie de colegios para señoritas, muchos de ellos dirigidos por educadoras extranjeras (Cañas-Dinarte 1999: 38-42). La Ley Orgánica y Reglamentaria de Instrucción Pública de 1885 establecía un curriculum más expansivo que abarcaba las siguientes materias: lenguas, aritmética, ciencias naturales e historia; pero no todos los colegios ofrecían esta gama de cursos y en los casos donde sí se ofrecían muchas internas no lograban completar el programa de estudio (Cañas-Dinarte 1999: 43-44). En una sociedad donde la educación femenina no era prioritaria la deserción escolar para contraer matrimonio y dedicarse a la familia no era vista con malos ojos.

Entre la intelectualidad masculina se apoyaba la educación de las mujeres pues se creía que la mujer tenía un rol moral que cumplir a nivel nacional como una especie de salvadora de la patria y educadora de sus ciudadanos. Un distinguido hombre de letras, Román Mayorga Rivas, alababa los avances de las mujeres que ahora comenzaban a 
incursionar en la universidad y otros terrenos antes vedados, diciendo que "en los países democráticos las mujeres son la salvación perpetua, la salud de la República" (Citado en Cañas-Dinarte 1999: 73). Otro contemporáneo con motivo del fallecimiento de la primera bachiller y doctora en ciencias del país, Antonia Navarro, promulgaba una especie de providencialismo femenino para salvar a la patria de "un cataclismo terrible" (citado en Cañas-Dinarte 1999: 83). Estas palabras, a nuestro ver, formaban parte de un discurso grandilocuente y de adulación por el ser femenino que se quedaba en pura retórica pues a nivel de estructuras e instituciones sociales y culturales no se veían cambios significativos para habilitar a la mujer en esa supuesta misión de redención nacional.

En las primeras décadas del siglo veinte parece haber dos vertientes con respecto a la educación de la mujer: la primera reproduce en su mayoría el mismo sistema anterior destinado a hacer de las jovencitas buenas administradoras del hogar y distinguidas damas de sociedad. Surgen varios colegios privados bajo el control de órdenes religiosas que además del curriculum tradicional enfocan la instrucción moral. ${ }^{2}$ Por otro lado, hay un intento por formar a algunas mujeres en oficios prácticos como telegrafistas y mecanógrafas. Este cambio se dio en respuesta a un decreto ejecutivo de 1891 que estipulaba establecer una escuela para preparar a mujeres en el ramo administrativo (Loucel 1937: 22). Pero los resultados limitados de este esfuerzo demuestran la gran resistencia que había en preparar a las jovencitas para formar parte de la fuerza laboral pública ofreciéndoles oficios diversificados.

Para los años veinte, época en que las mujeres a nivel mundial estaban ganando derechos ciudadanos, dicha renuencia se sentía cada vez más fuerte. Así lo demuestra un crítico del Colegio de Señoritas de Santa Ana, especializado en carreras no tradicionales, al 
declarar que "es poco fructuoso tanto afán en hacer tenedoras de libros a las señoritas cuando es en la pedagogía donde pueden hallar gran campo de acción para servir a la patria" (Arbizu, Diario de Occidente, 24/2/1928: 3). El articulista se queja de que las alumnas están aprendiendo las ciencias mientras los hogares van a la bancarrota porque las mujeres no saben administrarlos. Sugiere entonces que lo mejor para ellas son las clases de música, decoración, idiomas y moral (ídem).

Para aquellas mujeres audaces que rompieron con estos moldes educativos, al incorporarse a trabajos públicos, era difícil la convivencia con sus contrapartes masculinos que seguían creyendo que ese no era su lugar. Una noticia de la Prensa Gráfica correspondiente al 14 de septiembre de 1931 reportó que los empleados públicos no quieren a señoras ni señoritas en los puestos del gobierno. Esta actitud discriminatoria se debe en parte al temor y la ignorancia de muchos hombres de que las mujeres estaban invadiendo el terreno que tradicionalmente les pertenecía a ellos. Con reacciones como estas, a muchas jóvenes con deseos de desempeñarse en otros campos fuera de los convencionales en el hogar y la docencia, se les cortaron las opciones. Prepararlas para el matrimonio y la maternidad continuó siendo el objetivo principal de la denominada educación femenina a pesar de que comenzaban a abrirse espacios públicos donde las mujeres pudieran integrarse. Esta era una situación generalizada en toda Latino América a principios del siglo veinte como han apuntado estudiosas del tema (Lavrin 1978: 309; Miller 1991: $35-67){ }^{3}$

Las mujeres de la oligarquía vivían una situación aun más limitada. Estas ni siquiera podían plantearse estudiar carreras que les ofrecieran la posibilidad de tener un destino independiente del de esposa, madre y dama de sociedad prescrito para su clase. 
Aquí las limitaciones son más evidentes pues por regla general las familias vivían regidas por una serie de códigos sociales difíciles de romper. En el caso de las escritoras, algunas de ellas asistieron a colegios de señoritas para aprender sobre asuntos domésticos y otras materias como idiomas que se consideraban dignas de su clase social. Una educación en las letras es más probable que se llevara a cabo en el hogar con tutores particulares. Esto es lo que parecen indicar las biografías de algunas de las escritoras de las cuales tenemos noticias. A continuación nos referimos a la formación social y educativa de Claudia Lars narrada en su libro de memorias poéticas, Tierra de Infancia, donde hace observaciones muy pertinentes sobre la vida de mujeres de su entorno socio económico.

\section{EDUCACIÓN FEMENINA ENTRE LA CLASE PUDIENTE}

En Tierra de Infancia Claudia Lars nos abre una ventana hacia lo que podía esperar de su medio social y cultural una jovencita de familia adinerada como la suya a principios del siglo veinte. Al contar la historia de su familia relata que tanto la abuela materna como la madre fueron educadas en conventos ya fuera para hacerse religiosas si es que profesaban esta vocación o para convertirse en buenas amas de casa y esposas abnegadas. La educación que el convento les proveía las hacía más cotizables en su comunidad. Al egresar la abuela materna del convento de monjas ursulinas en Guatemala, la madre superiora constató que la joven “....sabe a perfección todo lo que una doncella cristiana y hacendosa tiene que saber. Casarla con un hombre bien establecido no me parece tarea

demasiado difícil...” (Lars 1969: 33). La educación de las mujeres de su clase implicaba, 
por lo tanto, una inversión para la familia, pues al darla en matrimonio a un hombre rico se aseguraba su posición económica y social.

Las mujeres en la familia de Lars no tuvieron otra alternativa más que seguir los papeles genéricos que les fueron asignados para de alguna forma socavar cualquier aspiración profesional que se despertara en ellas. La mujer de su clase social tenía que caber dentro de los patrones de conducta designados y no dar señales de una subjetividad propia. Una importante historiadora de los movimientos feministas en Latino América ha afirmado que a lo largo de la historia colonial y republicana, "...la meta para la mujer era la auto-nulificación, no la auto-afirmación..." (Miller 1991: 27). ${ }^{4}$ A la mujer, además, se le ha impuesto siempre el silencio como rasgo característico de su ser; de su madre, Lars recuerda que era "la silenciosa por excelencia" (Lars 1969: 209), en un hogar donde quienes poseían la palabra eran las figuras patriarcales.

En la generación de Lars, sin embargo, parece haber ya una voluntad de romper con esta situación que encasillaba a las mujeres en determinadas funciones. Las jovencitas compañeras de su infancia, por ejemplo, al sentirse atrapadas por el estrecho mundo rural en que vivían comienzan a hacer planes para cambiar su destino. Lars recuerda las palabras de una de ellas así: "...quiero conocer otros países y estudiar con la seriedad que estudian los hombres. ¡Deseo convertirme en una mujer con alguna profesión que sirva a los demás!..." (Lars 1969: 191). Jóvenes como estas fueron de hecho las primeras mujeres que salieron del país en busca de oportunidades educativas más amplias y que en algunos casos regresaron para mejorar la situación social de su pueblo. ${ }^{5}$ La norma general seguía siendo, no obstante, preparar a la mujer para las funciones que la sociedad patriarcal le había 
asignado aún cuando a nivel internacional se estaban viendo cambios significativos con respecto al papel que podía desempeñar en las sociedades modernas. ${ }^{6}$

La temprana formación literaria que obtuvo Claudia Lars no fue en el colegio donde estudiaba sino en su propia casa donde el padre, hombre que profesaba un gran interés por la literatura, le facilitaba libros. Debido al estímulo del padre pudo afirmar su vocación literaria, siempre y cuando se mantuviera dentro del marco de lo que se esperaba de ella como mujer, el matrimonio y la maternidad. En este sentido Claudia parecía correr la misma suerte de su madre y abuela. El padre después de proveerle una educación en el convento, pensaba casarla con alguien de su comunidad irlandesa en Estados Unidos. Se esperaba por lo tanto que sus actividades literarias fueran un complemento a su vida familiar y no un medio para independizarla de este destino. ${ }^{7}$

\section{LA DEFENSA DE LA ESCRITURA COMO QUEHACER FEMENINO}

A partir de los años veinte si bien se limitaba la incursión femenina en los oficios y carreras de corte público, en el mundo de las letras las mujeres comenzaron a ocupar un lugar cada vez más visible. Por primera vez se evidencian más nombres femeninos en los editoriales de periódicos así como en las páginas culturales. Forjarse un espacio en un mundo controlado por hombres, no fue sin embargo tarea fácil. Las mujeres tuvieron que hacer una férrea defensa de su oficio de escritoras negociando al mismo tiempo la identidad genérica como madre, esposa o hija que la sociedad les imponía.

Para aquellas con aspiraciones literarias y pertenecientes a clases acomodadas como la de Lars, el matrimonio y sus exigencias sociales y familiares representaban un obstáculo a su realización personal. Al casarse, como sostenía una intelectual de la época, muere la 
creatividad y subjetividad de las mujeres por el simple hecho de llevar un nombre que no es el suyo (Valle, El Imparcial, 27/11/1930). En otras palabras, el matrimonio le impone a la mujer una nueva identidad, moldeada en base a las expectativas del hogar y la familia. En su nuevo rol social siendo mujer casada, la escritora se sentía limitada pues no era bien visto escribir sobre temas que no tuvieran relación con el espacio inmediato del hogar y los asuntos considerados "femeninos".

Lo anterior tiene su aplicación en el caso de Lars cuya vida matrimonial detuvo su carrera poética y por consiguiente su propio desarrollo como mujer intelectual. Su producción de los años veinte cuando estaba recién casada es escasa. Fue entonces a fines de la década cuando vio la necesidad de adoptar el pseudónimo de Claudia Lars que le dio una nueva identidad, independiente de la de mujer casada donde se le conocía como Carmen Brannon de Beers. En una entrevista otorgada a una revista guatemalteca Lars explica toda esta problemática de la siguiente manera:

“...Cuando comencé a escribir, hace ya muchos años, me movía en un medio demasiado conservador. Era casi pecado que una muchacha educada especialmente para procurarse un buen marido y vivir la cómoda vida de una señora burguesa tuviera la audacia de expresar en público sus ideas sobre el amor, la belleza, la moral establecida. Mi nombre personal era una limitación a mi libertad expresiva y debía buscar un nombre para esconder mis próximos atrevimientos. Llegué hasta guardar silencio por unos años..." (Diario el mediodía, 11/31/946: 5)

Con su nueva identidad se asoman unos años de una prolífica actividad literaria, pero al mismo tiempo llegan también el divorcio y las luchas económicas por labrarse un futuro para sí y para su hijo en un ambiente donde pocos escritores podían vivir de su oficio.

El caso de Lars es indicativo de que la libertad de expresarse creativa y libremente representa para la mujer un paso en la búsqueda de su propio destino y la definición de su 
identidad. Es indiscutible que Lars ve en la escritura un espacio fundamental en su formación como sujeto. Al referirse a la poesía dice lo siguiente: "...creo que sin la merced de su acercamiento jamás hubiera podido realizar, dentro de mí misma, ni el más pequeño esfuerzo de superación..." (Lars 1969: 194). La escritura la libera, la expone en sus múltiples complejidades como ser humano, permitiéndole así conocerse mejor y explorarse a la vez que explora el mundo a su alrededor.

La poeta María Loucel (1899-1957), contemporánea de Lars y que en la década del cuarenta se convertiría en una prominente feminista, vio también en la escritura un medio para afirmar su identidad. En el siguiente poema titulado "Sospecho que estás loco" se dirige sarcásticamente al hombre que quiere truncar su expresión como poeta:

¿Que no escriba más versos? Sospecho que estás loco para pedirlo en tono de quien demanda poco.

¿Será que me ves triste cuando fabrico un verso O que mi ritmo juzgas a la poesía verso?

Me da igual, no podría llegar a complacerte. Es como si pidieras que no mate la muerte.

Es como si desearas que un hijo concebido permanezca en la entraña por tiempo indefinido.

Mi verso es el engendro de un dolor homicida. me horroriza el amante pero su hijo es mi vida

Y si la luz le niego porque me nace feo como una mala madre me sentiría reo

del pecado monstruoso contra naturaleza y soy madre perfecta en virtud de terneza.

Ya ves que no podría llegar a complacerte que es como si pidieras que no mate la muerte cuando inconciente pides que el hijo concebido 
permanezca en la entraña por tiempo indefinido.

(Loucel, Revista Nosotras, No. 74, 11/1937)

Loucel explora en este poema una serie de problemáticas asociadas con la escritura de mujeres. Alude por un lado a la falta de calidad que su interlocutor ve en su verso y por el otro al sentimentalismo potencialmente peligroso que se asociaba en la época con la literatura femenina. Loucel, sin embargo, al declarar que le da igual lo que piense su crítico reclama la escritura como algo propio, como una actividad sin la cual no puede vivir. Iguala su verso a un hijo que aunque surja del dolor y resulte deforme, siempre lo querrá. Al caracterizar a su poema en términos maternales, la hablante poética proclama estar afín con lo que se espera de la mujer, la procreación. Postula entonces, que la poesía no tiene por qué ser concebida como una tarea ajena a la mujer y su rol procreador. Al contrario, representa para ella un proceso vital, una actividad que le permite combatir la muerte. Por eso hay que darle vida como se da a luz a un hijo.

El poema habla en un lenguaje basado en una experiencia típicamente femenina que el hombre no conoce, la maternidad. Esta técnica tiene una estrecha relación con la denominada "écriture feminine" donde teóricas francesas han argumentado que la mujer escribe desde su propio cuerpo y alude a las experiencias reconocidas como femeninas con el fin de crear un contra discurso al pensamiento patriarcal hegemónico (Jones 1991: 361). ${ }^{8}$ Más allá de las controversias que han desatado estas teorías diferenciadoras que postulan un universo distinto para la mujer, en este caso escribir desde lo femenino representa un acto de poder. En la experiencia materna reside precisamente la autoridad que establece Loucel al pronunciarse poeta. Como mujer dadora de vida se siente en todo su derecho de 
experimentar con las palabras que en su caso representan una nueva forma de existir y de recrearse con un lenguaje propio y no el que le impone la sociedad.

Amparo Casamalhuapa (1910?-1971) enfrenta de otra manera a quien intenta socavar su vitalidad creativa. Para esta escritora, maestra y reformadora social la escritura es uno de los caminos en la búsqueda de la verdad y la justicia social pero es también un espacio en el que el individuo expresa su sensibilidad. En uno de sus pensamientos poéticos, titulado "Se prohibe mirar al infinito", el infinito es ese espacio donde la escritora encuentra su material lírico: "...se prohibe mirar al infinito, al infinito que se torna mínimo en el cáliz de una flor, dulce en la garganta del pájaro, dolorido en las lágrimas de un niño..." (Casamalhuapa 1938: 28-9). Casamalhuapa considera dicha prohibición por parte de su interlocutor una blasfemia. Es como quitarle parte de su ser pues en sus palabras, el infinito es donde "...se dilata mi fe y mi valor, donde mi anhelo cobra fuerza y mi grito juega a la ronda de las cosas sin límite..." (Casamalhuapa 1938: 29). En su incredulidad ante tal prohibición le recuerda a su interlocutor, al igual que lo hace Loucel, que ella posee una fuerza creadora afín con el mundo natural: "... soy el impulso que hace crecer el árbol y cresparse la honda..." En esta dinámica, concibe a su interlocutor como a un niño que no ha podido entender la profundidad de su espíritu y su sensibilidad artística.

Como intelectual abriéndose paso en la esfera pública a Casamalhuapa le toca muy de cerca la problemática social de la mujer salvadoreña. En su escritura denuncia los males sociales como el machismo, la ignorancia y la falta de oportunidades educativas que mantienen a la mujer y a la familia por extensión en una situación vulnerable. Por medio de sus escritos, Casamalhuapa intenta no sólo educar a sus lectores sobre estos problemas apremiantes sino también busca aliados que la apoyen en sus causas sociales y educativas. ${ }^{9}$ 
Escritoras de la talla de Amparo Casamalhuapa y Prudencia Ayala, en quien ahondaremos más adelante, usan varias tácticas para autorizar su posición y legitimar su oficio en una sociedad que insistía en no darles cabida en la esfera pública. Ambas se proclaman escritoras acudiendo a una especie de vocación divina que los hombres no pueden destruir. Al enfrentar las adversidades que se interponen en llevar a cabo su misión se amparan en la autoridad divina que según ellas las protege. Así, Casamalhuapa en momentos de duda recurre a ese ser supremo que cree haberla escogido como escritora:

“...Señor ¿por qué me diste un corazón impetuoso y un pensamiento claro? ¿Por qué hiciste nacer entre mis inquietudes un anhelo de justicia si no me es dado exigir que se cumpla? Es acaso para que gocen los hombres viéndome soñar imposibles y para que una madre se aleje diciéndome 'tú sólo eres una golondrina indefensa'? !Una golondrina; Señor, ¿es que valen tan poco las alas? ¿Para que me las diste si no he de volar con ellas? [...] ¿Por qué no me hiciste compañera del hombre que trabaja para comer y perpetuar una raza de esclavos?" (Casamalhuapa 1938: 10-11).

Casamalhuapa contesta estas interrogantes empleando una voz que pretende ser la de Dios quien le explica que el sufrimiento es una vía necesaria para llegar a la purificación del espíritu; por lo que le aconseja seguir en la lucha que se ha trazado, pues esa ironía de la que ella se queja, la de tener las armas para luchar y no poder emplearlas, es precisamente lo que renovará sus fuerzas: "...la ironía de las cosas hechas es el pincel en que la humanidad se revive..." (Casamalhuapa 1938: 11-12). El gran obstáculo para Casamalhuapa en la realización de su misión como escritora que defiende los intereses de los humildes y que lucha por la integridad y transparencia de los procesos políticos, no es la sociedad misógina en sí, sino el poder tiránico que regía al país. Debido a su crítica del sistema tuvo que salir al exilio dejando incompleta su labor social. ${ }^{10}$ 
En el caso de Prudencia Ayala, una escritora que persigue fines políticos muy definidos, se puede observar también esa insistencia en la autoridad divina para legitimarse como mujer pensadora en la polis. En ella tenemos todo un discurso profético que la guía como escritora. En sus escritos explora, sin temor de represalias, esta esfera de conocimiento que le ha sido vedado a la mujer cristiana. ${ }^{11}$ En realidad, nunca se declara en contra de la Iglesia, pero en el simple hecho de escribir profecías y al internarse en el mundo de lo desconocido subvierte toda una serie de reglas impuestas al cristiano y que tienen que ver con una filosofía de aceptar la vida según se presenta con todas sus adversidades. Con sus profecías cuestiona al mismo tiempo todo un sistema social y político corrupto que de no transformarse seguirá siendo fuente de injusticias perpetradas en particular en contra de las mujeres. El uso que hace de la escritura, en fin, sirve para combatir todo tipo de males sociales que se interponen al progreso de su patria y del proyecto unionista centroamericano que ve como salvación para las naciones ístmicas.

Mientras este grupo de escritoras formadas en los albores del siglo veinte tenía cierta conciencia de la discriminación social y cultural de la mujer, con respecto al feminismo, como se conocía en los años veinte, no expresaban opiniones muy audaces, salvo en el caso de Prudencia Ayala. Parte de su indiferencia hacia dicho movimiento se debía a que en la prensa de la época éste solía recibir muy mala propaganda como inmoral y anti femenino. Las escritoras entonces se encontraban en una encrucijada pues por un lado tenían una cierta conciencia de la necesidad de integrar más activamente a la mujer al quehacer de la nación y hacerla una partícipe más visible en los procesos socio culturales, mas por el otro lado, temían que se les acusara de ser mujeres con una moral sospechosa, 
percepciones que se asociaban con las feministas occidentales que tanto escandalizaban a los defensores del estatus quo para la mujer y para la institución de la familia.

Hay que ponderar, además, el hecho de que muchas de estas figuras aunque exhibían una conducta no conformista, eran producto de su propia socialización como mujeres en una sociedad patriarcal; por lo que en ciertos casos, inconscientemente promovían las mismas imágenes femeninas que las mantenían confinadas al espacio privado. La mayoría de ellas, al igual que otras escritoras latinoamericanas contemporáneas, creía que el destino de la mujer seguía radicando en la maternidad, de tal manera que llegaron a atribuirle a su sexo una inherente sensibilidad hacia todo lo que tuviera que ver con el aspecto emotivo humano. ${ }^{12}$ A continuación examinamos algunas de las actitudes hacia el feminismo que imperaban en el ambiente periodístico salvadoreño con el fin de situar en el contexto social de la época las posturas de estas escritoras.

\section{RECEPCIÓN Y ACTITUDES HACIA EL FEMINISMO EN LOS AÑOS} VEINTE

Las décadas de los veinte y treinta se consideran un período clave en el desarrollo del movimiento feminista internacional. Para las mujeres latinoamericanas estos años fueron de suma importancia pues con el triunfo del sufragio femenino en Estados Unidos en 1920 y en Inglaterra en 1928, los congresos feministas latinoamericanos que venían reuniéndose desde 1910 recibieron un nuevo impulso (Miller 1991: 73). El foro internacional les permitía a las mujeres formar alianzas para presentar resoluciones ante sus respectivos gobiernos solicitando reformas tocantes al tema de la mujer (Miller 1991: 82). El gobierno 
salvadoreño, respondiendo a los llamados internacionales, envió a escritoras de la talla de Alice Lardé de Venturino a encuentros feministas como el efectuado en Argentina en 1925. Estos fueron, sin embargo, gestos aislados que no tuvieron seguimiento a nivel local. ${ }^{13}$

En la prensa de la época se nota, en cambio, una interesante actividad en torno al tema. Las revistas y periódicos revelan algunas pautas del por qué había tanta renuencia a aceptar el feminismo. Se opinaba que dicho movimiento es una extravagancia del mundo occidental y que por lo tanto no le atañe a países marginales como El Salvador. Por otro lado los editorialistas más perspicaces reaccionan desde una posición conservadora, alertando al país sobre los peligros a la moral y al estatus quo que conllevaban estas nuevas ideas. En pocas instancias se ve este fenómeno cultural y social como una realidad y necesidad de los tiempos cambiantes.

El problema fundamental que se desprende de estas opiniones es la ignorancia sobre las metas del feminismo. En general, se conocían mejor los estruendos que el movimiento estaba provocando en Norteamérica que las posturas de las feministas latinoamericanas. El proyecto feminista latinoamericano de estos años enfatizaba la importancia del rol de madre para la mujer y pedía cambios que mejoraran su condición dentro de esta capacidad. Al contrario del feminismo europeo y norteamericano, se creía que la mujer no debía buscar la igualdad con los hombres pues su misión en la vida era diferente (Miller 1991: 74). ${ }^{14}$ El sufragio en estos inicios no era por lo tanto una de las metas principales como sí lo era capacitar a la mujer para un mejor desempeño en la educación de los hijos y la gerencia del hogar.

Una hojeada a algunos números de Excélsior, Revista ilustrada de variedades, que comienza a ser difundida a mediados de 1928, nos da una idea de cómo se concebía a la 
mujer salvadoreña de estos años. En general, las imágenes vertidas en esta revista, así como en las páginas femeninas de los principales periódicos nacionales, son muy tradicionales. No sorprende entonces que la mujer de estas revistas y otros medios masivos no existe por ni para sí misma sino en su función de esposa y de madre. En el rol de esposa se le aconseja ser discreta, "...no asediar al marido con preguntas enfadosas ni privarlo de sus deseos..." Debe usar sus supuestas habilidades femeninas para "...no imponérsele sino insinuársele...." En pocas palabras, se propone un modelo de mujer pasiva y cohibida; una mujer que sacrifica sus propios deseos para hacer feliz al marido y mantener la paz hogareña. $^{15}$

Si bien en la prensa general hay artículos en los que se expresa apoyo por la educación de la mujer, ésta se percibe como un accesorio más para un mejor cumplimiento de su papel en el ámbito familiar. Este es un caso clásico en la historia de las mujeres latinoamericanas cuyas respectivas sociedades favorecían su educación siempre y cuando no entrara en conflicto con sus tareas domésticas (Lavrín 1978: 12). Como se ha señalado, la educación de la mujer salvadoreña de principios del siglo veinte se reducía a artes manuales y a materias tocantes a la administración del hogar. Educarla más allá de este curriculum implicaba aceptar su salida del espacio hogareño, cosa que en la época se consideraba un atentado contra la moral. De hecho, las actitudes más reaccionarias y sensacionalistas clamaban por un "retorno a la feminidad" para evitar los peligros de caer en la "inmoralidad del mundo occidental" cuyas bases familiares estaban en peligro a causa del éxodo de las mujeres del espacio doméstico para integrarse a la vida pública (Diario de Santa Ana, 19/6/1929). Se seguía postulando, por consiguiente, que lo mejor es que la 
mujer salvadoreña continuara en su rol de "reina del hogar" donde se creía que residía su verdadera vocación. $^{16}$

Los temores que se traslucen en toda esta actividad periodística se refieren fundamentalmente a la posibilidad de que las mujeres lleguen a adquirir conciencia sobre su condición de oprimidas y que consecuentemente quieran cambiar las jerarquías genéricas vigentes hasta la fecha. Por otro lado, se expresa el absurdo pánico de que las mujeres "lo están invadiendo todo", y así se les niega la oportunidad de abrirse camino en la arena pública. Existe además un miedo irrefrenable de que al unirse a los hombres ya sea en calidad de compañera de trabajo o de estudios, estas adquirirán "cualidades masculinas." En los pocos espacios donde se les da cabida es con el estigma de objeto decorativo y sexual:

“...La mujer ha brillado más en el cine que en otros campos de la cultura pues es allí donde tiene oportunidad de lucir talento, cultura y lo más importante en ella... su belleza física, los encantos de que está dotada, el argentino timbre de su voz, el fuego de las miradas..." (Blanco, Excélsior, 23/21929: 13).

Muchas mujeres que escriben para revistas o para los periódicos conciente o inconscientemente perpetúan también estos modelos sexistas, lo cual demuestra de acuerdo con Carmen Naranjo, que “...la mujer es el blanco preferido de los mecanismos socializantes interesados en perpetuar en ella los aspectos más conservadores del orden social...” (Naranjo 1981: 92). Las páginas femeninas de los periódicos de la época, llenas de mujeres cuya vida parece girar en torno a la moda del momento, son testimonio de dicha socialización. Abundan por un lado las imágenes de mujeres frívolas que aceptan el rol de objeto de belleza y por otro lado están los segmentos dedicados a la madre abnegada y los 
consejos sobre la crianza de los hijos. Cuando aparece una imagen de una mujer liberada casi siempre es en son de burla o censura.

Cualquiera que fueran las opiniones expresadas en los medios masivos, lo cierto es que en toda esta actividad se estaban forjando ciertos espacios donde replantearse la organización de la sociedad y el lugar de la mujer en ella. Esto lo posibilitó la década del veinte con sus acelerados cambios sociales, políticos y económicos a nivel mundial. Y aunque las opiniones que surgían en la prensa salvadoreña no eran muy favorables a la causa feminista, las acaloradas discusiones en torno al tema lo hicieron circular en la esfera pública. Fueron escritoras feministas como Prudencia Ayala, cuyas gestas representan los primeros esfuerzos públicos a favor de la mujer de los cuales se tiene noticia en el país, quienes mantuvieron el debate en el foro nacional a lo largo de las décadas del veinte y treinta.

\section{PRUDENCIA AYALA Y LA DEFENSA DE LOS DERECHOS} FEMENINOS

Entre las escritoras de la época se destaca Prudencia Ayala debido a su espíritu combativo e inquebrantable. Pero, ¿qué posibilitó el surgimiento de una figura de su talante en el conservador ambiente cultural y social que hemos venido discutiendo? Esta mujer de origen humilde ${ }^{17}$ no se sentía restringida por cuestiones de clase social ni por su género. Tenía un fuerte sentido de su subjetividad aprendido de la madre, una fuerte y audaz luchadora de la causa unionista centroamericana. La madre le mostró una manera independiente de vivir como mujer siendo madre soltera y dueña de un pequeño negocio 
que le permitía dedicarse al mismo tiempo a asuntos políticos. La figura materna por lo tanto contribuyó a que en el pensamiento feminista que Ayala desarrollaría no entrara el modelo tradicional de la feminidad, entendido éste en el rol de esposa y madre abnegada. Ayala despojó el discurso femenino de sus asociaciones con el espacio privado y en su lugar postuló que la liberación de las mujeres implicaba ubicarlas en un terreno público desde el cual pudieran luchar por el bienestar nacional y regional. La plataforma unionista le permitió desarrollar sus estrategias e incursionar en la cerrada arena política nacional.

Desde una edad muy temprana Ayala se dio a conocer a través de las profecías que publicó en periódicos de su natal Santa Ana sobre el destino de las naciones centroamericanas. En éstas criticaba la tiranía de los gobiernos locales, el imperialismo norteamericano y todo aquello que se opusiera al ideal de unión. Como hemos señalado, el hecho de escribir profecías constituye desde luego un acto subversivo pues implica un desplazamiento de la temática y género literario prescrito para la escritora de principios de siglo que consistía en una poesía de tonos románticos o tocante a lo doméstico, la naturaleza y la maternidad (Carrera 1956: 230). ${ }^{18}$ Ayala defiende estos "atrevimientos" alegando que escribe por don divino: “...profecías, luces que Dios me revela para predecir la suerte de las naciones y [la suerte] en que los políticos deben orientarse..." (Ayala 1928: 164). De esta manera, autoriza el corpus de su escritura haciendo que sus declaraciones sean difíciles de refutar.

Pero no todos en el medio periodístico salvadoreño tomaron su trabajo adivinatorio en serio. Sus detractores se burlaron de ella tachándola de demente, denominación que Ayala apropió para llamar la atención sobre sus causas políticas y feministas. Prueba de esto es que en el título de su primer libro, Inmortal, Amores de loca, (1925), donde reúne 
su primera obra, se auto denomina "loca", declarando que si a su amor por el ideal de unión y fraternidad se le quiere llamar disparates pues que así sea (Ayala 1928: 25-27). ${ }^{19}$

La actitud negativa por parte de los críticos de Ayala demuestra el pánico que se genera al tratarse de cuestiones de género y particularmente cuando está de por medio una figura desestabilizadora que cuestiona el estatus quo con respecto a la mujer. Es práctica común como ha apuntado la intelectual feminista Sylvia Molloy, que a aquellos sujetos que se resisten a los discursos hegemónicos y a la conducta prescrita por las instituciones se los patologiza y se los deja fuera de todo aquello que no cabe dentro de las construcciones de ciudadanía. ${ }^{20}$ La "diferencia" y renuencia de Ayala a conformarse a la conducta prescrita para su sexo es en definitiva lo que la hace loca ante los ojos del patriarcado. Como ha sugerido otra feminista, la mujer debido a su otredad encarna la demencia que es a su vez la ausencia de la feminidad (Felman 1975: 8)..$^{21}$

Toda la crítica recibida fortaleció el empeño de Ayala en llevar a cabo su misión. A lo largo de la década del veinte se destacó por sus reclamos en favor de los derechos de las mujeres, acto que veía estrechamente ligado al triunfo del unionismo porque según ella no podría haber armonía entre los pueblos del istmo mientras sus mujeres permanecieran en los márgenes del quehacer político. Al hacer sus demandas se amparaba en el hecho de que sus compatriotas centroamericanas siempre habían luchado al lado de los hombres defendiendo los ideales soberanos frente a intereses imperialistas. Entonces no ve por qué se le debe negar a la mujer acceso a la vida política con pleno goce de los derechos que concede la ciudadanía.

Como máxima muestra de su fe en la mujer como sujeto político, Ayala se lanzó como candidato a las elecciones presidenciales de enero de 1931 respaldándose en el hecho 
que la constitución liberal de 1886 no estipulaba por sexo quien es ciudadano con derecho a elegir y ser elegido. Con este novedoso acto tomó por sorpresa a toda la sociedad capitalina salvadoreña que nunca se había planteado el hecho de que la mujer tuviera un rol activo en la cosa pública. Para Ayala, sin embargo, el momento histórico era idóneo para colocar en la agenda nacional el tema de los derechos femeninos pues el país estaba viviendo una apertura democrática bajo la presidencia de Pío Romero Bosque (1927-1931). Es así como en carta al presidente declara sus intenciones:

"...Tomando en cuenta la libertad [que] ha surgido en mi querida tierruca y no queriendo que el sexo femenino permanezca fuera de la ley restringida de los derechos de ciudadano, lanzo mi candidatura para Presidente de la República, inspirada en la justicia de un gobierno mixto que identifique la soberanía de la nación en los dos sexos..."22

La prensa de la época convirtió este caso en la sensación del día y en su mayoría se dedico a burlarse del "atrevimiento" de tan audaz mujer. Algunos periodistas indagaron en su estado psicológico nuevamente haciendo de ella blanco de acusaciones de demencia. Otros la vieron como la feminista loca con ansias de poder. Ayala por su parte gozó de toda la atención que la prensa le prestaba. Les daba a los periodistas la novedad del día que andaban buscando concediéndoles entrevistas y permitiéndoles que la acompañaran en sus actividades de campaña. Como toda una hábil mujer política, Ayala se tomó todo el proceso con una buena disposición, no queriendo enajenar a nadie ni contrariar a sus adversarios. Sabía que no tenía la más mínima posibilidad de ganar pero para ella el simple hecho de estar en la contienda hasta haber agotado todos los recursos jurídicos representaba un logro. 
La corte ante la cuál presentó su demanda que se le reconociera como ciudadano terminó dictaminando que la Constitución de 1886 al declarar que "son ciudadanos todos los salvadoreños mayores de 18 años, los casados y los que hayan obtenido algún título literario" se refería únicamente a los del sexo masculino. Este veredicto era predecible pues como ha apuntado Jorge Cáceres Prendes, “...en la sociedad salvadoreña de la época reinaba el sobreentendido cultural que las mujeres estaban excluidas del ejercicio de los derechos políticos...” (Cáceres 1995: 271). Ayala llevó su caso hasta la Corte Suprema donde los magistrados en su mayoría llegaron a las mismas conclusiones aunque no de manera unánime (Moreno 1997: 12-13).

Desafortunadamente, este proceso quedó truncado a partir del año 1932 cuando el país entraría en el largo período del militarismo y las dictaduras. Con la cruenta represión desatada en contra de los sectores progresistas de la sociedad se ahogaron los medios para que un movimiento de carácter feminista floreciera en el país a pesar de que Ayala ya contaba con un contingente de apoyo. Sus últimos días los dedicó a tratar de cambiar las leyes en el código civil que no ofrecían ningún tipo de amparo jurídico a la mujer pues no se le reconocía como un sujeto independiente del padre o el marido. ${ }^{23}$ Ayala murió en 1936 sin ver su sueño de unión e igualdad entre los sexos coronado. Su trayectoria feminista, aunque no tuvo resultados inmediatos, representa, no obstante, un ejemplo de la sagacidad política femenina puesta al servicio de la mujer salvadoreña de la época. Sus actividades sentaron además un importante antecedente en el largo camino que había de recorrer la lucha por los derechos femeninos en El Salvador. ${ }^{24}$ 


\section{CONCLUSIONES}

Si las mujeres no tenían la libertad de crear cambios en la vida pública del país durante la década del treinta y posteriormente, siguieron no obstante aferrándose a los pocos espacios privados donde sí podían expresarse aunque fuera desde la perspectiva de lo que se consideraba apropiado para su sexo. Nos referimos aquí en particular a la poesía donde muchas de las escritoras de la época encontraron un terreno fértil donde plasmar sus inquietudes personales y sociales. Claudia Lars y Amparo Casamalhuapa, por ejemplo, se dedicaron a escribir sobre las madres y los niños desvalidos haciendo una crítica de las injusticias sociales que no permitían que se viviera en armonía y con igual acceso a los bienes nacionales. Estas mujeres nunca dejaron de presentarse públicamente como madres, esposas o educadoras por lo que tuvieron bastante aceptación en el seno nacional. Este apego a la construcción social de la feminidad casi como un culto, ha sido fuerte para muchas mujeres latinoamericanas, lo cual ha llevado a Francesca Miller (1991) ha identificarlo como un punto de diferenciación entre las feministas latinoamericanas de principio de siglo y las norteamericanas y europeas:

“...En lugar de rechazar su rol de madres y esposas, definido por la sociedad, las feministas latinoamericanas se puede decir que son mujeres cuyas acciones van en protesta de las leyes y condiciones que puedan poner en peligro su habilidad para cumplir con su papel..." (Miller 1991: 74). ${ }^{25}$

No porque las feministas latinoamericanas, incluidas las escritoras, se rigieran por estos postulados, debemos dejar desapercibido su trabajo, pues es precisamente desde el espacio de lo femenino que muchas lograron conquistar nuevas esferas socio-culturales y políticas. Este es sin duda el caso de Mistral quien en sus primeros escritos contenidos en 
Lecturas para mujeres defiende el rol social de la mujer como el de la madre y educadora de sus hijos (Mistral 1924: 12) para luego declarar que ésta no puede ni debe desvincularse de la política. ${ }^{26}$

En El Salvador, aunque es normalmente desde los papeles tradicionales como el de la madre y la maestra, que las escritoras alzan su voz de protesta, el recrudecimiento de la situación política a fines de la década del treinta y principios del cuarenta contribuyó a que las mujeres se concibieran a sí mismas también como sujetos ciudadanos. En su toma de conciencia vieron abiertas las posibilidades para la mujer de desempeñar otros roles con el fin de crear sociedades verdaderamente democráticas.

Este rasgo estaba presente ya en Prudencia Ayala quien desde principios de los años veinte, con los eventos políticos en torno a la dinastía de los Meléndez en el Salvador y la dictadura de Manuel Estrada Cabrera en Guatemala, se lanzó a la esfera pública proclamando que el pueblo se alzara para combatir la injusticia. Así mismo, Casamalhuapa, que se desenvolvía en la docencia durante los primeros años del Martinato, atacó al sistema tiránico en que vivían los salvadoreños. Estos ejemplos son indicativos de cómo el entorno sociopolítico hizo que las mujeres que estaban en ciertas posiciones culturales privilegiadas se sintieran llamadas a forjar cambios sociales ya fuera a través de su escritura o la militancia política.

Para algunas de estas escritoras las ideologías reivindicadoras de la época como el socialismo eran problemáticas. Muchas veces preferían desvincularse de ellas debido a la propaganda negativa que los gobiernos militares les daban y la persecución que sufrían sus seguidores. Algunas intelectuales como Lars, aseveran repetidamente no estar afiliadas a ningún partido en particular. Lo mismo decía Mistral al identificarse, como "...el 
fenómeno de una mujer sin partido político..." (Quezada 1994: 162). A veces adoptaban esta actitud precisamente para protegerse de represalias; tal el caso de Casamalhuapa que en el prólogo a su obra, El joven sembrador, dice lo siguiente: "advierto al lector que nada tengo que ver con la ideología de casi todos estos escritos". Sin embargo, lo más probable es que siendo mujeres privadas de una experiencia política significativa no tuvieran el conocimiento suficiente para formular sus opiniones.

La mayoría de estas escritoras como buenas seguidoras del cristianismo social del pensador Alberto Masferrer, actúan más bien en nombre de un sentido de religiosidad que les exige la compasión y la caridad. En este sentido desempeñan el papel de "madres" de los desvalidos y cumplen así con una misión redentora que es básicamente el papel primordial que le atribuyen a la escritora. De todas ellas la que es más decisiva en sus posturas feministas es definitivamente Prudencia Ayala, quien aparte de su escritura le ha legado a la mujer salvadoreña un inquebrantable espíritu de lucha a pesar de las más terribles adversidades.

Se necesitó de la segunda guerra mundial y del despertar de la conciencia política nacional de un buen número de mujeres salvadoreñas para que el feminismo echara las raíces que habrían de sostenerlo en pie en las décadas siguientes. Las líderes fueron nuevamente escritoras como María Loucel y Matilde Elena López que tuvieron que reanudar esta lucha. en un contexto político en que ya no se podía ignorar la actuación de las mujeres como agentes de cambio. Por fin, en 1950 se les otorgó el derecho al voto sin restricciones y se garantizó su acceso a la educación y la cultura en general de manera equitativa con el hombre aunque en la realidad esto no se materializó como estipulaban las leyes. 
En todo el proceso político, cultural y social de la primera mitad del siglo, la intelectualidad femenina salvadoreña desempeñó un papel capital a pesar de que aparte de uno que otro nombre las escritoras suelen estar ausentes de la historia cultural hegemónica del país. Cuando se estudian sus contribuciones se hace además desde una óptica muy limitada viéndolas como escritoras de una poesía que enaltece el rol de madre sin considerar que aun en estos discursos maternalistas están propulsando ideas sociales y políticas. Lars, Loucel, Casamalhuapa y Ayala con distintas metas, hicieron una decisiva defensa de su derecho a la letra para forjarse una identidad personal como escritoras pero también para crear cambios en la vida de las mujeres a quienes representaban. Como grupo deben figurar en la historia literaria de la época con un espíritu libre e insosyugable aun a pesar de las circunstancias sociales y políticas que insistían en contener su radio de acción al espacio privado. Queda entonces pendiente un trabajo que dé cuenta de manera sistemática de la producción creativa de estas escritoras con especial énfasis en sus esfuerzos por avanzar la causa femenina y crear cambios en las percepciones que se tenían con respecto a la mujer.

\section{BIBLIOGRAFÍA}

Arbizu, Néstor. 1928. "Por fin tendrá Santa Ana el establecimiento que necesita, Sección normal en el colegio de señoritas." Diario de Occidente, 24 de febrero, 1928. Ayala, Prudencia. 1925. Inmortal, amores de loca. San Salvador: Imprenta Arévalo. 1928. Payaso literario en combate. San Salvador: Imprenta Arévalo.

Carlos Blanco. 1929. "Las mujeres son así. Excélsior (San Salvador) No. 1 (37): 13. 
Cáceres Prendes, Jorge, 1995. "Género ciudadanía y cultura política en El Salvador: 19301959" en Identidades nacionales y estado moderno en Centro América. San José, C.R.: Flacso, pp. 269-281.

Cañas-Dinarte, Carlos. 1999. "Las hijas de Minerva. Notas para una historia educativa y cultural de las mujeres salvadoreñas, Premio único de Ensayo.

IV Juegos Florales Nacionales, Casa de la Cultura de Panchimalco-CONCULTURA, El Salvador.

Carrera, Julieta. 1956. La mujer en América Escribe. México: Ediciones Alonso.

Casamalhuapa, Amparo. 1938. El joven sembrador. San Salvador: Talleres Gráficos Cisneros. 1971. El angosto sendero. San Salvador: Tipografía Ungo.

Escobar Galindo, David y Luis Gallegos Valdés, 1976. Poesía femenina de El Salvador. San Salvador: Dirección de Publicaciones.

Felman, Shoshana. 1975. "Woman and Madness: The Critical Phallacy", Diacritics (1975): 2-10.

Gallegos Valdés, Luis. 1996. Panorama de la literatura salvadoreña. San Salvador: UCA Editores. Cuarta edición.

Gold Janet. 2000. "Historias de vida, historias de literatura" en Visiones y revisiones de la literatura centroamericana. Jorge Román Lagunas, compilador. Guatemala: Editorial e Impreofset Oscar de León Palacios.

Herrera Frimont, Celestino. 1946. "Claudia Lars en la poesía de América". Diario el mediodía, 3 de noviembre, 1946.

Lars, Claudia. 1969. Tierra de infancia. San Salvador: Dirección de Publicaciones, 1969. Segunda edición.

Lavrin, Asunción. 1978. "Introduction" y "Some Final Considerations on Trends and Issues in Latin American Women's History" en Latin American Women: Historical Perspectives. Asunción Lavrín, ed. Westport, Connecticut; London, England: Greenwood Press, pp. 1-20; 303-332.

Loucel, María. 1937. "Sospecho que estás loco", Nosotras (Guatemala) No. 74. Reseña general de representativos femeninos en el reino de Cuzcatlán [sin referencia editorial]

Mayorga Rivas, Román. 1885. Guirnalda salvadoreña, Colección de poesías de los bardos de la República de El Salvador. Tomo II. San Salvador: Imprenta del Dr. Francisco Sagrini.

Miller, Francesca. 1991. Latin American Women and the Search for Social Justice. Hanover \& London: University Press of New England.

Mistral Gabriela. 1924. Lecturas para mujeres. México: Departamento de Educación. 1994. Escritos políticos. Selección, prólogo y notas de Jaime Quezada. México: Fondo de Cultura Económica.

Moreno, Elsa. 1997. Mujeres y política en El Salvador. Costa Rica: FLACSO.

Naranjo, Carmen, comp. 1981. La mujer y el desarrollo. La mujer y la cultura. México: UNICEF, Secretaría de Educación Pública. 


\section{NOTAS}

${ }^{1}$ La universidad nacional fue establecida a mediados del siglo diecinueve. Pero solo en 1888 egresa la primera mujer con título universitario en el campo de la ingeniería. Su nombre era Antonia Navarro (18701891). Murió pronto después de haber concluido su carrera sin poder ejercerla. Mujeres en la literatura salvadoreña, San Salvador: Red de mujeres escritoras, 1997, p. 9.

${ }^{2}$ Para una lista completa de estos colegios, véase las páginas 88-89 de la obra de Carlos Cañas Dinarte, Las hijas de Minerva.

${ }^{3}$ Para más sobre la educación de las latinoamericanas en general consúltese el tercer capítulo, "Women and Education in Latin America," del libro de Francesca Miller, Latin American Women and the Search for Social Justice, Hanover y Londres: University Press of New England, 1991, pp. 35-67.

${ }^{4}$ Esta así como todas las citas posteriores de este libro son mi traducción: "the goal for women was selfeffacement, not self-affirmation."

${ }^{5}$ Lars se refiere brevemente a Consuelo Suncín, una inquieta joven de su natal Armenia quien salió del país pasando por Guatemala, México, Argentina, países donde se empapó de toda la rica actividad cultural de los años treinta en adelante (1969: 193-4). Termina en Francia durante la segunda guerra mundial, casada con el conde Antoine de Saint Exupery, célebre autor de El principito. Esta mujer se dedicó a la pintura y escultura. Para más sobre su interesante vida, véase sus propias Memorias de Oppède, traducidas del francés por Ricardo Lindo, San Salvador: Dirección de Publicaciones e Impresos, 1998; y La Rosa que cautivó al principito por Abigaíl Suncín, San Salvador: Talleres Gráficos UCA, 2003.

${ }^{6}$ Las mujeres menos afortunadas económicamente seguían ejerciendo oficios tradicionales como el de maestra que no les permitían gozar de la independencia económica que una carrera le proveería a un hombre. El ejemplo de "la niña meches," institutriz de Claudia y de su hermana, es evidencia de la situación económica precaria que vivían las maestras en la época, ganando sueldos miserables. El relato de Meches aparece en las páginas 79-84 de Tierra de Infancia.

7 Todos los datos sobre la vida de Lars han sido tomados de Tierra de Infancia y suplementados con los estudios que Carmen González Hughet ha hecho sobre su vida y obra. Véase la introducción a Claudia Lars: Poesía completa I y II, San Salvador: Dirección de Publicaciones, 1999.

${ }^{8}$ Las ideas provienen del clásico artículo de Ann Rosalind Jones, "Writing the body: Toward an Understanding of L'écriture Féminine" en Feminisms: An Anthology of Literary Theory and Criticisms, Robyn Warhol y Diane Price Herndl, eds., New Jersey: Rutgers University Press, 1991, pp. 357-370. Jones se refiere particularmente a las teorías de Hélène Cixous, Julia Kristeva, y Luce Irigaray que aunque difieren en varios aspectos, basicamente están de acuerdo en que las experiencias del cuerpo femenino representan un lenguaje opuesto al discurso falogocéntrico, p. 361.

${ }^{9}$ La obra socio-literaria de Casamalhuapa consiste básicamente del libro, El joven sembrador (1938), producto de sus ideas inspiradas en el vitalismo del pensador, Alberto Masferrer. Este libro es interesante para trazar el desarrollo público de la mujer escritora. Su segunda obra, El angosto sendero (1971) es una especie de autobiografía de los años vividos en el país hasta 1938 cuando tenía 28 años. En entrevista con su hijo, el Dr. Rolando Marroquín (San Salvador, 30 de junio de 1999), éste reveló que más allá de la personalidad que se perfila en sus dos obras, Casamalhuapa fue en muchos sentidos una mujer fuera de lo común; se convirtió en una feminista comprometida con su pueblo a pesar de estar lejos de éste y fue una madre dedicada por completo a la familia, tanto así que sacrificó una carrera como escritora. Nunca se olvidó del sufrimiento que padecía el pueblo salvadoreño, pues desde el exilio en México enviaba contribuciones a periódicos que se pronunciaron en contra de la dictadura. Al enterarse del inminente derrocamiento de Martínez fue a unirse a otros exiliados en Guatemala. Volvió al país en los últimos años de su vida donde murió en 1971.

${ }^{10}$ Debido al clima de terror político que vivía el país en la década del treinta, no pudo tomar posturas muy militantes en nombre de las cruzadas que tanto le interesaban. Era consciente que desafiar abiertamente al gobierno y sus políticas represivas en contra del pueblo implicaría peligro a su persona. Sin embargo, al verse frente a una oportunidad de denunciar públicamente al gobierno absolutista de Maximiliano Hernández Martínez, no pudo desistir de dicho acto. Cuando el 29 de agosto de 1939, Casamalhuapa es invitada a hacer una ofrenda floral y dar un discurso en conmemoración de un prócer de la independencia centroamericana, 
ella transforma el evento en una protesta pública. Habla del presente gobierno que lejos de seguir el modelo de los héroes nacionales, hace gala de su tiranía (1971: 39-42). Tenemos entonces a una escritora que muy al contrario de lo que se esperaba de ella como mujer, está dispuesta a arriesgar su propia vida en aras de la libertad de su pueblo.

${ }^{11}$ Como es bien sabido a lo largo de la historia a la mujer con dotes de profeta o mística se le ha catalogado de bruja o demente. Las mujeres que se han venturado por estas vías de conocimiento, han tenido que demostrar con creces sus dones. Ejemplo típico de esto es Santa Teresa de Avila quien usó su escritura para comprobar ante las autoridades eclesiásticas la legitimidad de sus visiones.

${ }^{12}$ Estas contradicciones son fuertes aún en poetas como Alfonsina Storni que se habían declarado feministas. Véase al respecto el artículo de Gwen Kirkpatrick, "The Journalism of Alfonsina Storni: A New Approach to Women's History in Argentina" en Women Culture and Politics in Latin America, Berkeley: University of California Press, 1990, pp. 105-129.

${ }^{13}$ Alice Lardé de Venturino participó más tarde en 1927 en el Congreso Internacional Femenino a Favor de la Paz (Brasil), Carlos Cañas Dinarte, Diccionario escolar de Autores salvadoreños. San Salvador: Dirección de Publicaciones e Impresos, 2000. María Alvárez de Guillén Rivas por su parte fue delegada a la Comisión Interamericana de Mujeres en 1929. Su postura feminista parece encontrar su fuerte en la necesidad de educar a la mujer en campos no tradicionales como el científico y abrirle las puertas en el mundo de las artes donde según ella se le sigue considerando "novicia." Véase "Labor Feminista," Diario de Santa Ana, 18/6/1929.

${ }^{14}$ Asunción Lavrin por su parte sostiene que para el caso argentino, el énfasis del feminismo no era tanto en el sufragio sino en las reformas sociales tales como el control de la prostitución y el alcoholismo, leyes que protejan a mujeres y niños en el trabajo y un relajamiento de las restricciones impuestas al estatus de la mujer en el código civil. Latin American Women: Historical Perspectives, London, Westport: Greenwood Press, 1978, p. 13.

15 "Errores que cometemos con los hombres" Excélsior, No. 2:80, (1929), p. 11.

16 Véase el artículo de Carlos Blanco, "Las mujeres son así", Excélsior, No. 1:37 (1929), p. 13. Véase además "Mujeres en el Hogar," Diario de Occidente, 30/5/27 p. 3, donde la autora de la sección, "Cuartilla Femenina" se queja de la liberalidad y frivolidad de las mujeres, contra lo que prescribe que no salgan de sus hogares.

$17 \mathrm{Al}$ contrario de otras escritoras de la época, Ayala no provenía de la clase pudiente. Con respecto a su educación se sabe que cursó los primeros dos años de la primaria con lo que se puede afirmar que es básicamente auto didacta Carlos Enríquez Consalvi, Prudencia Ayala: hija de la centella (obra en progreso).

${ }^{18}$ Ayala como mujer de su tiempo también escribe poemas de tono romántico como los que produjo en momentos en que su espíritu se sentía decaído debido a la persecución inflingida en su persona. Estos constituyen sin embargo una parte mínima de su obra y aparecen en su libro Inmortal, Amores de Loca que es una especie de collage de todo lo que había escrito hasta 1925, fecha de su publicación.

19 Todo esto lo defiende Ayala en su segundo libro de 1928, Payaso literario en combate que reúne toda la crítica a su persona, su obra y sus proyectos.

${ }^{20}$ Estas declaraciones fueron hechas por Molloy durante una conferencia presentada en la Universidad de California en Berkeley, 21 de octubre de 1998.

${ }^{21}$ Existe un importante corpus crítico sobre el tema de la mujer y la locura desde la pionera obra de S. Gubar y M. Gilbert, Mad Woman in the Attic: the Woman Writer and the $19^{\text {th }}$ Centuy Literary Imagination, New Haven: Yale University press, 1979.

22 lunes 28 de ----- 1930. En el recorte periodístico proporcionado por el Museo de la Palabra y la Imagen de San Salvador, no se pueden leer ni el nombre del periódico ni la fecha completa. Nuestra sospecha es que esta carta la envió Ayala por el mes de junio de 1930 desde Guatemala antes de salir para su patria.

${ }^{23}$ Estos planteamientos aparecen en una hoja volante titulada "En pro de los derechos individuales de la mujer ante el mundo civilizado en la augusta Asamblea Legislativa nacional de la República de El Salvador en la América Central: la mujer salvadoreña defiende sus derechos" Imprenta R. Delgado: Santa Ana, junio 16 de 1931. Al pie de la página Ayala designa que está hablando en nombre de Santa Ana, El Salvador y América Central apuntando con esto a su visión unionista. Es decir, que la causa de la mujer salvadoreña era a su vez, según ella, la de todas las centroamericanas.

${ }_{24}$ Para más sobre la trayectoria de Ayala así como la de las escritoras mencionadas en este estudio, consúltese mi disertación doctoral titulada Historia, feminismo y literatura: escritoras salvadoreñas 19201960, Universidad de California Berkeley, 2000. 
${ }^{25}$ La cita en inglés dice así: Rather than reject their socially defined role as mothers, as wives, Latin American feminists may be understood as women acting to protest laws and conditions which may threaten their ability to fulfil that role.

${ }^{26}$ En una ocasión dijo: "Voy convenciéndome de que caminan sobre la América vertiginosamente tiempos en que ya no digo las mujeres, sino los niños también, han de tener que hablar de política, porque la política vendrá a ser (perversa política) la entrega de la riqueza de nuestros pueblos; el latifundio de puños cerrados que impide una decorosa y salvadora división del suelo; la escuela vieja que no da oficios al niño pobre y da al profesional a medias su especialidad”. Gabriela Mistral: Escritos Políticos, Selección, prólogo y notas de Jaime Quezada, México: Fondo de Cultura Económica, 1994, p. 228. 